\title{
64 \\ HUMAN FACTORS IN SOFTWARE DEVELOPMENT - CURRENT PRACTICE RELATING TO USER CENTRED DESIGN IN THE UK
}

\author{
Andrew Smith and Lynne Dunckley \\ Department of Computing and Information Systems, \\ University of Luton, Park Square, Luton, LU1 3JU, UK \\ Tel : $058234111 \quad$ Fax: 0582489212 \\ Email : ASMITH @VAX2.LUTON.AC.UK
}

\begin{abstract}
KEY WORDS: user centred design, organisational issues, participation
\end{abstract}

\begin{abstract}
Effective user engagement is perceived as a vital ingredient in the successful take-up of Information Technology projects. However, there has been little documented evidence as to how far, and in which ways, commercial systems designers within the UK are adopting user-centred design (UCD) principles. This paper provides an overview of the issues involved, and through the identification of three concepts within user-centred design (structures, processes and scope), presents the results of a survey of organisations representing, the most significant body of evidence available within the United Kingdom as to the extent of, and problems associated with UCD.
\end{abstract}

\section{INTRODUCTION}

In the UK it appears that recently a number of IT projects would still appear to be failing because of a lack of effective user engagement. The aim of this research project was to investigate to what extent user-centred design principles have been integrated into commercial IT systems design. In order to achieve this aim a survey of organisations within the UK was completed. The objective of the survey was to identify which particular aspects of user-centred design (UCD) are being adopted at a faster rate than others and to ascertain a number of factors which influence the degree of user-centredness in both UK organisations and IT projects.

\section{USER CENTRED SYSTEMS DESIGN}

It is suggested that approaches to user-centred design can be addressed under the following broad concepts:

structures, processes, and scope.

It is these concepts which have been used within the survey to analyse approaches to UCD.

Structures to support the design process include project management, design team structures, and mechanisms for user involvement and communication between the design team and the user community.

Processes for design focus around the design methodology and include issues relating to requirement elicitation, communication and implementation, including prototyping. 
The scope of the design process relates to how far the analysis and design reflects a socio-technical, as opposed to just a technical, solution. More specifically an IT project with only a narrow scope will focus on technical and functional requirements whereas one with a wider scope will address issues such as the allocation of function between man and machine, the design of work structures and individual jobs and ways of enhancing job satisfaction.

The user centredness of the large number of system design methodologies available is well documented (Holman, 1988, Robbins 1989). In addition a range of Human Factor tools are available at various stages in the life cycle, for example in Task Analysis (Fountain, 1985, Shepherd 1989), or by using the HUFIT PAS tool-set approach (Galer et. al. 1989).

\section{PREVIOUS RESEARCH}

There is only a limited body of evidence available in the literature relating to UK practice. Two sources are, however, of note. Firstly, Hornby and Clegg (1992) describe a study of the processes of participation during the design and implementation of a new computer-based information systems at a large UK bank. The essential finding was that although user project managers claimed that they were committed to the goal of effective user-participation, the end user's view was rather different. In their Productivity Enhancement Programme (PEP) the Butler Cox Foundation (now CSC Index) have investigated the rather more limited User Involvement in Systems Development. Green (1992) reveals that 98 per cent of organisations 'consider the involvement of users to be an important aspect of their development practice' and that over 70 per cent claim to 'use methods that support user involvement' but that under 20 per cent support 'active' involvement.

\section{THE SURVEY}

Although it would be possible to approach a number of interested parties within the systems development arena it was decided, for the purpose of this project, to focus on the individual within commercial user organisations who has the overall responsibility for the introduction of IT systems. In choosing just one group of personnel within the development process it is accepted that results may not produce a fully representative picture of what is actually happening on the ground. It is possible that their views may not accord with that of the end users themselves.

The survey itself was organised in two stages. Firstly a postal survey was distributed to a sample of UK companies. One fifth took part in telephone 'follow-ups' which were conducted both to validate individual postal questionnaires and to substantiate conclusions drawn. The postal survey instrument was organised under broad topics (design method, project management, user requirements, prototyping, organisational issues) with individual questions within categories mapping to the concepts of UCD (structures, processes and scope).

\section{RESULTS}

The overall results obtained for each of the three UCD concepts (structures, processes and scope) suggests that there is far more movement towards the use of user centred structures than towards a wider organisational scope in design.

\subsection{STRUCTURES}

Most progress towards user-centredness is being made within the area of structures to support the overall process. A large majority of organisations make attempts to support and involve the user. Over three quarters involve end users, where projects are led by a partnership between users and designers. Structures are far more extensive at the organisational and formal representative level, rather than at the detailed local design level. The problems associated with further developing user oriented structures relate to the difficulty in seconding appropriately skilled personnel.

\subsection{PROCESSES}

Whilst it emerged that traditional design methods still dominate the design process, the survey has shown that a wide variety of other methods, providing a range of user engagement, are in use. Structured methods are in use in approximately one third of projects with one fifth adopting 
SSADM. Whilst Information Engineering, and Soft Systems are used in a significant number of organisations, there is no evidence of the take up of specific participative methodologies. Whilst the shift to structured methods has come about mainly for reasons of efficiency and effectiveness within the design process it has also led to a significant increase in user involvement.

Emphasis within user requirements is given to high level issues (e.g. Business Mission and Strategy) and less so to low level ones (e.g. Task Execution). There is evidence that some importance is given to organisational issues (e.g. Job Design / Work Structures). Whilst there is evidence of methods for task analysis and for the use of scenarios or dramas / story boarding, the majority use no formal method for eliciting or specifying requirements, relying exclusively on verbal interviews and natural language recording mechanisms. Prototyping was found to be the most well supported potential UCD topic. Whilst the main reason for prototyping was to ensure system functionality, it is interesting to note that $38 \%$ used prototyping for interface design and that $24 \%$ say that prototyping was extended to the non-technical issues of work structures and processes. Although vertical and horizontal prototypes are used in equal proportions, evolutionary prototypes exceed exploratory ones by a factor of two to one.

\subsection{SCOPE}

Organisational issues is the area where least progress is being made towards a user centred approach. Whilst over $70 \%$ cite partnership. between users and designers to be important, only one fifth are specifically able to integrate social and technical issues. There is evidence that implementers are aware of the need to widen the scope of design but feel that organisational priorities and senior management policies negate against them making progress.

\section{COMPARATIVE ANALYSES}

The sample was split into two sub-sets; those where all the IT expertise was provided from within the user organisation and those where the IT expertise was primarily provided by an external consultancy. By performing separate analyses for the two sub-sets the results indicate that the use of external consultants has a negative effect on user centredness.

Results show that small companies would appear to be as likely to be user-centred in all aspects as large multi-nationals with medium sized organisations lagging behind. Perhaps large organisations have the resources to support UCD whilst small ones find it inherently much easier.

There are a number of other possible underlying factors such as organisational policy, the individual skills and policies of the designer, type and size of the organisation / project, and use attitudes. Whilst at this stage it has not been possible to address all these issues an attempt has been made to further investigate the effects of the nature of both the organisation and project. Each of the participants within the sample was placed within one of three groups for Organisation Type (Manufacturing / Production, Service / Retail, Other) and one of five groups for Project Type (Payroll / Personnel, Stock Control, Sales Order Processing, Finanace / MIS, Other).

From the subsequent analysis it would appear that organisations primarily providing a customer service, as opposed to manufacturing a product, tend to be more user-centred. This suggests organisations with direct access to the public tend to adopt a more user-centred approach to design. The results also indicate that Finance / MIS systems are more user-centred than Sales Order Processing (other figures too small to draw conclusions). The dominant feature is perhaps project type and particularly project size. It could be postulated that the two issues of organisation type and project type constitute some indicator of interactiveness: a service / retail company and a large cross-organisation MIS system are likely to be more interactive. Clearly further evidence is required here to substantiate and further develop this area of the work.

\section{CONCLUSIONS}

Clearly not all of the UK IT industry is approaching UCD in the same way or at the same pace. The Survey would indicate that the 
state of play of UCD in UK industry can be summarised as follows:

'Systems design and implementation is becoming more user-centred. This is occurring in part indirectly as a result of a shift towards structured methods such as SSADM. Systems Designers have a commitment to user involvement which goes further than requirement elicitation. Blocks to the further development of UCD include management policy and styles, user skills and priorities together with a lack of resources. Usercentred principles are not being adopted uniformly across the IT industry. Firstly there is a disparity in the speed and depth of the adoption of the different aspects or concepts within UCD. Whilst structures are increasingly common, and processes are developing, organisational issues are largely ignored. The second consideration influencing the uniformity of introduction relate to factors inherent in the specific company and project. A large number of influences are present but in particular it would appear that companies providing a customer service are more usercentred. Cross organisation projects also lead to more user-centredness. It seems likely that there is a relation between the interactiveness of the project and the degree of user involvement. Overall approximately one fifth of organisations / projects demonstrate a genuine practical usercentred approach'

\section{ACKNOWLEDGEMENT}

The writers would like to acknowledge the support provided by Professor Ken Eason at Loughborough University of Technology.

\section{REFERENCES}

Fountain, A. J. 1985, Modelling User Behaviour with Formal Grammar. In People and Computers: Designing the Interface. Proceedings of the British Computer Society Human Computer Interaction Specialist Group. (Cambridge University Press)

Galer, M, Taylor, B et al 1989, The HUFIT Toolset. Human Factors in IT. In Contemporary Ergonomics, Proceedings of the Ergonomics Society's 1989 Annual Conference (Taylor and Francis, London)

Green, P. 1992, Involving Users in Systems Development, Butler Cox Product Enhancement Programme Paper 19 August 1991. (CSC Index, London)

Holman, R. 1988, Integrating Human Factors into the Systematic Development Process. The State of the Art and the Future. In Contemporary Ergonomics, Proceedings of the Ergonomics Society's 1988 Annual Conference (Taylor and Francis, London)

Hornby, P. et al 1992, a, User Participation in Context: A Case Study in a UK Bank. In Behaviour and IT, 1992, Vol. 11, No 5. (Taylor and Francis, London)

Mumford, E. 1983, Participative Systems Design: Practice and Theory. In Journal of Occupational Behaviour. Vol. 4. 1983.

Robbins, I. 1989, The Contribution of Structured Systems Design. In Participation in Systems Development: UNICOM Applied IT Reports. Ed. Ken Knight (Kogan Page)

Robson, J, et al 1991, Systems Analysis and Design Methodologies: Are these methods addressing Human Issues. In Contemporary Ergonomics, Proceedings of the Ergonomics Society's 1991 Annual Conference. (Taylor and Francis, London)

Shepherd, A. 1989, Analysis and Training in Information Technology Tasks. In Task analysis for HumanComputer Interaction. Ed Dan Diaper (Ellis Horwood) 